\title{
A ilha do mar Atlante, de Juan Tomás Ávila Laurel: autobiografia e ciberativismo ensaístico na Guiné Equatorial
}

\author{
Ana Lúcia Sá*
}

\begin{abstract}
Resumo
Neste texto, dedicado ao escritor Juan Tomás Ávila Laurel, destaca-se a sua posição no campo da literatura da Guiné Equatorial, por se tratar do escritor crítico da ditadura de Teodoro Obiang com mais visibilidade internacional que vive no país, circunstância que ganha contornos mais marcados devido ao seu ciberativismo. Baseando-se essencialmente em registos ensaísticos e no romance autobiográfico Arde el Monte de Noche, este texto procura problematizar, de acordo com o projeto de compromisso social que subjaz à produção escrita de Juan Tomás Ávila Laurel, a colonialidade vivida por uma parte da humanidade, bem como a emergência de vozes e de ações que subvertem os quadros de ausências dos condenados da terra em atuais sistemas de dominação e de univocidade.
\end{abstract}

Palavras-chave

Guiné Equatorial. Autobiografia. Colonialidade. Compromisso social.

\begin{abstract}
"Y llegó la ola devoradora de vida y con ella pasó una cosa en aquel sitio donde trabajaba, en su hospital, en el hospital del pueblo grande, cuando supo lo que podía ser aquella enfermedad, abrió todos los cajones, todas las cajas, los armarios, las vitrinas y no encontró nada que supiera o pudiera combatir con aquel terrible mal. Siguió buscando, pues la necesidad era imperante. Pero lo único que encontró lo usó a manos llenas."
\end{abstract}

Arde el Monte de Noche, p. 101

Este texto, na sua primeira versão, tinha outra epígrafe e outro início. Começava por explicar o lugar destacado de Juan Tomás Ávila Laurel na atual literatura da Guiné Equatorial, ao ser o escritor crítico do regime ditatorial de Teodoro Obiang Nguema a viver no país com mais visibilidade no mercado literário internacional. E a manter um

\footnotetext{
* Centro de Estudos Africanos - ISCTE/IUL. Fundação para a Ciência e a Tecnologia. E-mail: analuciasa@gmail.com.
} 
blog a que deu o nome de Malabo, fincando desta forma a sua inscrição no ciberativismo ${ }^{1}$.

A epígrafe era esta: "Todo en $\mathrm{mi}$ isla daba miedo. En realidad vivir en la oscuridad es hacerlo de espaldas a la historia. $Y$ es que no creo que nadie pueda contar lo que hace en la oscuridad, pues no conocería todos los detalles de lo que ocurre en ella" (Arde el Monte de Noche: 158). E através dela iniciava um percurso sobre o medo, sobre a arte da escrita condicionada, sobre duas ilhas do Atlântico como lugares de enunciação discursiva: a ilha de Ano Bom (naturalidade de Juan Tomás Ávila Laurel) e a ilha de Bioko (lugar de vivência do escritor). Contudo, o tema do medo chegou de outra maneira no dia 11 de Fevereiro de 2011. E agora explico a razão para ter elegido outra passagem do romance autobiográfico Arde el Monte de Noche para iniciar este texto. Ela fala da determinação de um desesperado médico com poucos recursos para pôr fim a um surto de cólera que assolou a ilha de Ano Bom, algures no tempo da infância do autor.

Não conseguiu. Mas, nesta passagem, poderemos ler a personalidade de Juan Tomás Ávila Laurel ${ }^{2}$. A determinação em empreender ações, ainda que solitárias, move Juan Tomás Ávila Laurel no combate a injustiças, a incompreensões e a privações. Assim aconteceu no referido dia 11 de Fevereiro. Sozinho, sem comunicação prévia, decidiu iniciar uma greve de fome. Com esta ação, um protesto pacífico contra a ditadura de Obiang nascia em Malabo.

O dia escolhido coincidia com a renúncia de Hosni Mubarak no Egito, diante de uma Praça Tahrir plena. E com uma visita oficial do Presidente do Parlamento Espanhol, José Bono, à capital da Guiné Equatorial, a quem dirigiu uma carta, na qual apelava a uma intervenção com vista a propiciar uma mudança no regime e a saída de Obiang, o líder de uma "dictadura que nos come el alma"3. Mas foi mais longe, não ficando apenas pelos pedidos de uma intervenção que levasse à saída de Obiang e família do país.

Um homem afastado das organizações políticas formais apresentou de forma clara um projeto político para o seu país, que passa pelo investimento nas áreas da saúde, educação, agricultura ou justiça. Projeto este que poderá encontrar um resumo na frase com que Juan Tomás Ávila Laurel termina o seu livro de ensaios Cómo Convertir este País en un Paraíso (2005: 85): "Por una Guinea Mejor".

Com esta missiva e com este protesto, Juan Tomás Ávila Laurel pretendia captar a atenção não só dos políticos espanhóis, mas também do que poderemos chamar de "comunidade internacional". De facto, conseguiu-o. E num momento em que Obiang é o Presidente da União Africana, implicando um maior foco sobre um país que se considera ainda muito desconhecido. De imediato, começaram a circular notícias sobre este protesto, sobre a falta de liberdade de expressão na Guiné Equatorial ou sobre a oposição política ao regime levada a cabo dentro e fora do país, em plataformas como a Convergência para a Democracia Social - o partido da oposição que conta com um

1 O blog de Juan Tomás Ávila Laurel pode ser consultado no endereço eletrônico: http://www.fronterad.com/?q=blog/18.

${ }^{2}$ Devo esta ideia a Eva Cabré, a quem agradeço.

3 A carta de Juan Tomás Ávila Laurel a José Bono foi-me enviada pelo autor por correio electrónico no dia em que começou a greve de fome e consta como anexo a este texto. 
deputado na Assembleia Nacional, sendo os restantes do Partido Democrático da Guiné Equatorial - ou o vasto grupo de intelectuais exilados, entre os quais se integra Donato Ndongo, outro escritor trabalhado neste volume.

Com uma produção literária abundante, dedica-se a vários géneros ${ }^{4}$. E é ainda o editor da revista de artes e literatura Atanga, publicada pelos Centros Culturais Espanhóis da Guiné Equatorial, instituição na qual, aliás, trabalhava, antes de se deslocar a Barcelona, cidade na qual deu por terminada a greve de fome, empreendendo outras lutas e consciencializando-se da imprescindibilidade da sua vida na entrega a uma causa que abraçou e que une cidadãos da Guiné Equatorial e de outros países.

Num contexto no qual as livrarias são ausentes ${ }^{5}$, as hipóteses de debate diminutas e o sistema educativo deficitário, Juan Tomás Ávila Laurel surge como um dos autores mais destacados de um sistema que se considera marginal no amplo conjunto das literaturas escritas em África. E também o é por se tratar do único campo construído em espanhol, cuja maioria dos atores divulgados após a independência se encontra fora da Guiné Equatorial ${ }^{6}$.

Nascido em 1966, faz questão de marcar a sua filiação, em escritos e nas várias conferências que dá, tanto no seu país, como em Espanha ou nos Estados Unidos da América. Ele apresenta-se como filho de Manuel Ávila Fernández e de Luisa Laurel Bizantino. E como um escritor de Ano Bom: "nací en aquella isla y empecé a ser mayor en ella" (Arde el Monte de Noche: 188), rematando assim o facto de ter nascido fisicamente em Malabo e não em Ano Bom. Estas circunstâncias de eleição são determinantes para que possamos compreender essa "ilha do mar Atlante" e a construção de um saber geopolítico e social da diferença no mundo moderno atlântico.

Juan Tomás Ávila Laurel assinala a exclusão geral de um discurso histórico próprio, ao colocar a tónica no discurso centrado no poder político do país e em diversos tipos de graus de exclusão que poderemos verificar mais adiante neste texto. Mas a afirmação do discurso próprio obtém-se através da negociação de terrenos de ficção e de autobiografia, de história e de memória, de colonialismo e de póscolonialismo na constituição da memória insular e global.

${ }^{4}$ Entre os seus títulos encontram-se romances (La Carga, 1999; El Desmayo de Judas, 2001; Nadie Tiene Buena Fama en Este País, 2001; Avión de Ricos, Ladrón de Cerdos, 2008; Arde el Monte de Noche, 2009), contos (Cuentos Crudos, 2008), poemários (Historia Intima de la Humanidad, 2000), ensaios (El Derecho de Pernada, 2000; Cómo Convertir Este País en un Paraíso, 2005) e textos dramáticos (El Fracaso de las Sombras, 2004), citando alguns títulos.

$5 \mathrm{Na}$ cidade de Malabo, poder-seão adquirir escassos livros na livraria da Congressão dos Missionários Filhos do Imaculado Coração de Maria (Claretianos), bem como no Centro Cultural Espanhol (à semelhança do de Bata). No momento da escrita deste texto, não existe qualquer outra livraria, estando projetada e aceite uma por um grupo de cidadãos da Guiné Equatorial e de Espanha, com subvenção da Agência Espanhola de Cooperação Internacional para o Desenvolvimento.

${ }^{6}$ Entre os escritores da Guiné Equatorial que vivem no exílio encontramos os nomes de Donato Ndongo (autor de Las Tinieblas de tu Memoria Negra, 1987, ou El Metro, 2007), Francisco Zamora Loboch (Memoria de Laberintos, 1999), Juan Balboa Boneke (O Boriba, 1982, ou El Reencuentro: El Retorno del Exiliado, 1985), Justo Bolekia Boleká (com Löbëla, 1999) ou Juan Manuel Davies (autor de Siete Días en Bioko, 2007). Obras como as referidas catalizam a "tragédia nacional" - que José Fernando Siale Djangani (2010: 64-65) considera um "género literário" - escrita fora da Guiné Equatorial, dando nota do medo e da violência vividos dentro do país. 
O romance Arde el Monte de Noche transporta-nos ao universo das recordações de infância do autor, na década de 1970, passada na ilha de Ano Bom. Este romance de Juan Tomás Ávila Laurel pertence ao quadro de narrativas ficcionais autobiográficas centradas na infância, entre as quais encontramos Las Tinieblas de tu Memoria Negra (1987), do seu conterrâneo Donato Ndongo, Chiquinho (1947), do cabo-verdiano Baltazar Lopes, ou L'Enfant Noir (1953), do guineense Camara Laye. A peculiaridade de Arde el Monte de Noche em relação a estes romances reside no tempo eleito: o do pós-independência. A Guiné Equatorial já não era a Guiné Espanhola, constituída pelas províncias de Fernando Pó e Rio Muni. Era um país independente e vivia a ditadura de Francisco Macías Nguema, nascida a 12 de Outubro de 1968.

Ao trabalhar a autobiografia, o relato privilegia o ponto de vista pessoal, construindo campos de reflexão sobre a identidade insular e, mais ainda, providenciando fontes de um questionamento crítico a partir de uma posição e de uma construção geoparticulares do universo insular de Ano Bom. Assim, derruba a perspetiva da dicotomia que amiúde se explora sobre narrativas e feitos insulares coloniais (e o termo "coloniais" não apresenta aqui um sentido meramente temporal) assentes em periferia e metrópole e em pontos de vista de colonizado e colonizador ${ }^{7}$.

A marcação de uma identidade anobonense depende de fatores geomorfológicos, de ser ilha, mas também - e para mim principalmente - dependendo de fatores geoestratégicos e geo-identitários, dado o percurso histórico da ilha no marco do mundo atlântico e no marco do mundo guinéu-equatoriano. Ou seja, terá a ver com aspetos geográficos, mas vai mais além, como é visível no romance de Juan Tomás Ávila Laurel. A ilha de Ano Bom tem como caraterísticas essenciais ser a sua ilha, uma pequena ilha africana engolida pelo Atlântico, junto ao Equador e habitada por negros. Uma ilha da qual o autor desconhece as coordenadas geográficas, mas que nela vive ${ }^{8}$.

Neste romance, cruzam-se diversos campos de memória, desde a resistência à escravidão até à cativação da independência. Sendo esta ilha habitada ou não aquando do início do tráfico de escravos transatlântico ${ }^{9}$, é certo que a comunidade se inscreve na ferida colonial. Se assim não fosse, o narrador não salientaria o facto de ser habitada por negros. "La herida colonial no es ni más ni menos que la consecuencia de ese discurso racial" que se figura em tabelas de classificação e de categorização de grupos e de cores de pele (Mignolo, 2007: 97). É através da ferida colonial que os habitantes de Ano Bom se inscrevem no Atlântico Negro e na sua constituição moderna, se quisermos recuperar o olhar des-eurocentrado de Paul Gilroy em The Black Atlantic. Modernity and Double Consciousness (2002), ao consignar as caraterísticas de uma modernidade ocidental para a qual foram essenciais os africanos, por ela negados. Estamos, portanto, diante de um grupo nascido do encontro colonial e da violência que supunha o traslado para uma terra que não a própria. Filhos da

\footnotetext{
7 Para uma perspectiva crítica sobre a análise de narrativas insulares, consulte-se Garuba, 2001.

${ }^{8}$ Sobre as características da ilha de Ano Bom salientadas neste parágrafo, veja-se Arde el Monte de Noche, p. 11-12, 21, 34.

${ }^{9}$ De acordo com Justo Bolekia (2003, p. 28-29), é provável que a ilha que hoje conhecemos com o nome de Ano Bom fosse habitada antes do século XVI, baseando-se em relatos de origem que marcam a procedência de outras partes do continente africano. Já segundo Arlindo Caldeira (2009, p. 293), a ilha era deserta aquando da chegada dos portugueses, em 1492.
} 
ferida colonial que se encaixa à escravatura e ao sistema de exploração económica colonial, que fazia das ilhas um objeto de desejo colonial de posse para laboratório ou para passagem ${ }^{10}$, do qual não está ausente uma imagética do longevo e do isolado.

$\mathrm{O}$ isolamento de Ano Bom em relação ao restante território continental e insular que constitui a Guiné Equatorial adensa-se se a ele se aliar o esquecimento. Como salienta Juan Tomás Ávila Laurel, esse esquecimento isolou materialmente a população ambô, mas compensou-se pela presença das musas, que aí estão "para ayudar a los isleños a sobrellevar ese ominoso abandono" (ÁVILA LAUREL, 2009, p. 332). Este abandono económico e social tornou-se mais forte nestes tempos da memória de infância do autor, marcado também por condições políticas, já que a população ambô não votou em Francisco Macías Nguema nas eleições de 1968 (cf. BOLEKIA, 2003, p. $123,138)$.

Isto significa que a ilha de Ano Bom não pertencia ao nguemismo, à base que sustenta a pertença da Guiné Equatorial ao clã de Macías Nguema, da comunidade de língua e cultura fang, e que se carateriza pelas constantes violações aos direitos humanos, à confiscação ou ao nepotismo. Inclusive a ilha de Fernando Pó deveria designar-se "Isla de Macías Nguema Bidyogo", ditador que deveria ser saudado como "Único Dios, milagro y salvador del Pueblo guineano" ou "Gran Mesías". Masías Nguema foi derrubado no chamado Golpe da Liberdade, a 3 de Agosto de 1979 pelo seu sobrinho Teodoro Obiang Nguema, na altura, entre outros cargos, chefe das Forças Armadas e diretor da sinistra prisão de Black Beach, tendo sido posteriormente fuzilado (cf. BOLEKIA, 2003, p. 124, 134-139).

O nguemismo classifica-se como uma etnocracia, nas palavras de Juan Tomás Ávila Laurel, um forte motivo para fissuras na comunidade do país (2009, p. 441). Facto que se verifica na atualidade, com o predomínio e privilégio fang nos campos públicos, dos quais se destacam o político e o militar. No blog Malabo, através qual Juan Tomás Ávila Laurel exerce a função de ciberativista, a Guiné Equatorial é apresentada frequentemente como o reino republicanizado ou como a não-república de Teodoro Obiang Na crónica de 5 de Janeiro de $2010^{11}$, afirma claramente a confiscação do poder por parte da comunidade de língua e cultura fang, desde os primeiros momentos do país, em detrimento das demais. E assinala diversas formas de resistência, como a bubi, comunidade autóctone da ilha de Bioko, que em tempos coloniais fazia frente aos "hombres voraces" da trata de escravos. E que se juntam aos demais grupos perante os "pamues, que [...] se precian de que se les llamen fang", originários da região continental do que hoje é a Guiné Equatorial, e sobre os quais questiona: "¿Para qué querían ver el mar los pamues, hoy fang?"12. A pergunta que

${ }^{10}$ Sobre a imagem das ilhas para os exploradores, cf. GARUBA, 2001, p. 61. De assinalar que a ilha de Ano Bom era lugar de cultivo de algodão e de armazenamento de barcos e de escravos. $\mathrm{Na}$ época da conquista do Atlântico por parte das potências europeias, existem relatos sobre os processos de defesa de ambôs contra barcos holandeses e ingleses, contra o sistema de escravatura, cujos sucessos se demonstram pela experiência e domínio do mar (cf. BOLEKIA, 2003, p. 33, 44).

11 Intitulada "Planes para el sabático en Guinea Ecuatorial". Disponível em: http://www.fronterad.com/?q=node/375. Acesso em: dez. 2010).

12 Conforme se pode constatar nas crónicas dos dias 2 de fevereiro, 5 de Abril e 9 de Novembro de 2010. Disponíveis em: http://www.fronterad.com/?q=node/677, 
encerra em si todas as respostas associadas à cativação do poder contém igualmente a nota da apropriação do discurso de uma chamada unidade nacional, que é proclamada pelo clã de Obiang Nguema, fang originário de Mongomo. É deste grupo a propriedade do Estado e da retórica sobre uma unidade que obtém mais eco num sistema repressor (e este sistema não é apenas local, mas estendido ao sistema colonial global) colado ao poder político e realizado no quotidiano da população pelos militares, dispostos em barreiras que controlam saídas e entradas das principais cidades e o movimento nas povoações, que se faz não raro a troco de subornos que vão diretamente para os cofres individuais dos militares do Estado. Tudo isto poderá ser lido no blog que Juan Tomás Ávila Laurel escrevia aí, na Guiné Equatorial.

Como denunciada o autor sobre o qual este texto se centra, é este o mesmo grupo que celebra o programa Horizonte 2020, elaborado a partir do Partido Democrático da Guiné Equatorial. Trata-se de uma meta a atingir sempre postergada por irresoluções básicas do quotidiano de uma ditadura feroz que segue com o apoio de políticas realistas ocidentais, baseadas em interesses corporativistas. E este Horizonte 2020 carateriza-se por realizações como igualdade entre todos os cidadãos ou acesso a água potável ${ }^{13}$. Aliás, o problema do acesso à água é um dos temas mais trabalhados por Juan Tomás Ávila Laurel nos seus ensaios e crónicas do blog Malabo, associado às condições infra-humanas em que vive grande parte da população. É este o tema que inicia o seu livro de ensaios Cómo Convertir este País en un Paraíso (2005) e é o espelho da indignação pela localização da Guiné Equatorial numa das zonas com mais água no planeta.

A patrimonialização do Estado, a particularização nos seus dirigentes, as redes clientelísticas, a sua não institucionalização em relação à população que integra são rasgos muito trabalhados quando se trata de analisar a "questão estatal" em toda a África Subsariana ${ }^{14}$. Sendo uma realidade alógena que sofre pressões de ordem interna e externa, o Estado em África é um dos vetores de periferização das realidades do continente no atual sistema internacional de colonialidade. O cientista político congolês Mbuyi Kabunda (2007, p. 35-36) é perentório ao classificar este sistema como recolonizador, já que mantém diversas cadeias de exploração e de agressão, nas quais os Estados africanos se caraterizam pela subordinação, pela marginalização e por uma submissão a leis da democracia liberal. A mesma linguagem de incapacidade do Estado é aplicada por Mbuyi Kabunda (2007, p. 38-40) relativamente à legitimação dos regimes e à projeção de futuro. E nestas ligações temporais, Juan Tomás Ávila Laurel trata de paralelismos entre a situação atual de submissões e de resistências a poderes imperialistas que já não levam o nome de esclavagistas (como é exemplo a crónica intitulada Malabo, dedicada ao rei bubi do mesmo nome, datada de 21 de

http://www.fronterad.com/?q=node/1102 e http://www.fronterad.com/?q=node/2321), Acessos em: dez. 2010.

13 Mais especificações sobre o programa Horizonte 2020 poderão ser encontradas na crónica de 26 de Julho de 2010. Dipsonível em: http://www.fronterad.com/?q=node/1812. Acesso em dez. 2010.

${ }^{14}$ Como se poderá constatar em livros como os "clássicos": El Estado en África, de Jean François Bayart (Barcelona: Bellaterra, 1999), África Camina. El Desorden como Instrumento Político, de Patrick Chabal e Jean-Pascal Daloz (Barcelona: Bellaterra, 2001) ou Africa and the International System. The Politics of State Survival, de Christopher Clapham (Cambridge: Cambridge University Press, 2007). 
Dezembro de 2009), mas sim de donos do circuito petrolífero, em cujas mãos acaba por ficar manchada a falta de condições de vida básicas em termos de acesso a água potável e à habitação, bem como a falta de alternativas numa economia centrada na mono-exploração e na dependência de proventos externos.

E se falarmos de um mundo que por vezes se poderá apresentar como unidirecional para componentes unívocas - ou assentes em pressupostos e linguagens de civilização ou de desenvolvimento, que não poderão esconder a sua feição colonial e eurocentrada - de lógicas de dominação, outros temas terão de ser abordados. $E$, para tal, o romance Arde el Monte de Noche continua a oferecer-nos perspetivas outras.

Como se fosse um relato oral contado a outros, o autor justifica a sua posição num sistema logocêntrico no qual se inscrevem dois tipos de construção da dominação: a da escrita e a da preservação das tradições orais africanas a cargo de outros. Sobre esta segunda forma de dominação, é com ironia que o autor se atribui a impossibilidade de contar relatos do património imaterial da sua comunidade. Apenas pode oferecer o relato da sua infância e desta maneira inscrever-se e à gente da sua ilha, a comunidade de língua e cultura ambô, num conto recuperado por uma entidade alógena.

Quanto à primeira forma de dominação, a esta ligada mediante o logocentrismo, poder-se-á ramificar nas seguintes categorias: a negação do ofício de escritor e a língua.

As figuras que se categorizam na ilha de Ano Bom ficcionada em Arde el Monte de Noche como pertencentes ao universo do logocentrismo são o professor e o padre, para além do escritor, que Juan Tomás Ávila Laurel afirma não ser, numa interrupção de um episódio diegético do romance, que poderá ter a função de um epílogo e que serve para refletir estes laços associados ao logocentrismo (Arde el Monte de Noche, p. 226-228). É neste contexto que se destaca a língua fá d'ambô. A canção apreciada como a "más bonita del mundo intero" (Arde el Monte de Noche, p. 11) é uma presença constante no romance e no universo marítimo que ficciona ${ }^{15}$. Alewa é a palavra que aciona a ação masculina de colocar o barco no mar, de maneira a dominálo, seja para o ato de pescar, seja para estabelecer a comunicação entre a povoação mais pequena do sul com o pueblo grande, desafiando a orografia da ilha. É através desta canção que o narrador se torna não observante, apenas, mas participante: é pela língua que primeiro manifesta a total inserção do narrador individual no facto social total insular e na partilha de códigos de toda a população, em palavras que só existem ali e que só eles conhecem ${ }^{16}$.

A língua espanhola com que escreve o romance é o mecanismo de leitura da língua autóctone, manipulando-se deste modo os termos da construção imperialista da língua. Trata-se de um mecanismo de organização narrativa (espanhol) que tem ao nível da consciência do sujeito colonial a ferramenta para expressar este mecanismo

${ }^{15}$ É esta canção que dá o mote ao romance Arde el Monte de Noche (p. 11) e que é retomada em outras descrições do universo marítimo (v. g., p. 17-19, 194-206).

16 Como é exemplo a seguinte citação: "en las aguas de nuestra isla había um pez [...] que solamente tiene nombre en nuestra lengua. [...] Se llama pámpan'a" (Arde el Monte de Noche, p. 46). Mais adiante será especificado o que entendo por "facto social total insular". 
de resistência (fá d'ambô) aos elementos sistémicos de sujeição que encontramos na obra: a igreja, a escola e os militares.

Como recorda Chela Sandoval, em Methodology of the Oppressed (2000, p. 3536), vários grupos das margens (colonizados ou escravos, por exemplo) experimentaram e teorizaram a divisão entre significado e significante, não sendo uma caraterística que se possa aplicar, stricto sensu, a teorizações do pós-modernismo. Esta rutura deriva da consciencialização da sujeição ao poder e é através do corpo que estes limites da ordem social podem ser nomeados e feitos realidade. É assim que a "consciência diferencial" permite transformar este conhecimento num método. Esta consciência, para Chela Sandoval (2000: 140), liga-se a expressões não verbais, sendo o seu modo de acesso e interpretação o corpo como modelo de expressão múltipla, através de imagens, de sons, de gestos, de música. No contexto de Arde el Monte de Noche, encontramos diversas linguagens de resistência com base no fá d'ambô a exprimir sentimentos e lugares de opressão.

$\mathrm{Na}$ igreja, as mulheres "cantaban en nuestra lengua" a eucaristia. E a preposição especifica-se mais, já que são as "mujeres de nuestra lengua", contrastando com a doutrina, performada numa língua que não é propriedade de ninguém da ilha e que não gera formas de identificação (Arde el Monte de Noche, p. 90. Destacado meu).

Quanto à escola, surge como intermezzo a um relato sobre o universo religioso endógeno do Rey de Agua Salada, rei daquela ilha do "mar de Atlante", uma nomeação específica para registar a construção de um corpo semiótico próprio ${ }^{17}$. Aliás, as oferendas que se lhe faziam consistiam em produtos de produção local, como banana ou mandioca, e importados, como conhaque ou um rádio, que, no caso de serem "productos de los blancos", deveriam estar novos (Arde el Monte de Noche, p. 171-172). Encaixada nesta partilha do universo religioso de Ano Bom, encontramos a memória da escola, pautada por referentes distantes da realidade conhecida. Para além de métodos ideovisuais significativamente desligados de qualquer circunstância insular ${ }^{18}$, a escola é essencialmente um lugar que provoca medo, devido, em primeiro lugar, a ser o espaço que se associa à língua de dominação, no que contrasta com todos os espaços de liberdade associados à língua própria e que se abrem quando a escola termina (Arde el Monte de Noche, p. 166-168).

Sumariando os espaços eclesiástico e militar, poder-se-á concluir que a língua é mais do que expressão de liberdade: é o seu locus. E esta é a "lengua de la gente de mi isla" ou "la lengua de la gente de mar de Atlante" (Arde el Monte de Noche, p. 49, 108). Língua que não pertence ao terceiro grupo executor de dominação, os militares. As marcas distintivas dos soldados enviados para Ano Bom em relação aos habitantes da ilha permitem que nunca pertençam ao universo cujo chão é a base comum: não falam a língua da ilha e não sabem como manobrar artes marítimas:

17 Como se poderá verificar na seguinte citação: "Bueno, en la isla de mar de Atlante de la que hablo al rey del mar se le conocía como Rey de Agua Salada, así, y cuando oía a otros del rey de agua salada, sabía que se refería al nuestro, no al de otro sitio. En la lengua de nuestra isla existen dos nombres para el mar: mar, en dicha lengua, y agua salada" (Arde el Monte de Noche, p. 171).

${ }^{18}$ A título de exemplo, refira-se que a aprendizagem do abecedário ideovisual se realiza com referentes que não têm nada que ver com a realidade conhecida: " $b$ " é a letra associada a "burro", tal como "f" a "foca" ou "i" a "índio" (Arde el Monte de Noche, p. 166). 
"¿Pero cómo ellos podían ejercer bien de soldado en un lugar, en nuestra isla, donde no tenían a nadie, sin hablar nuestra lengua, sin saber nadar ni poder llevar un cayuco? [...] Los de nuestra isla tampoco aprendimos su lengua" (Arde el Monte de Noche, p. 74).

E esta atitude final é a mais destacada: a recusa em aprender a língua que configura a etnocracia da Guiné Equatorial.

Como se verifica através destes exemplos, a língua marca o que é autóctone e o que é hegemonicamente imposto nas redes do imperialismo que construiu o mundo atlântico. A bomba cultural que Ngugi Wa Thiong'o $(1987$, p. 3) cola à colonização e à sua empresa de destruição de todas as crenças e potencialidades de pessoas e de povos subjugados acaba por encontrar no universo da ilha do mar Atlante uma manifestação ambígua, atendendo ao que se vem explicando sobre a língua. Ou seja, se, por um lado, a língua fá d'ambô é uma criação devida ao sistema colonial escravocrata atlântico, por outro lado, é através desta língua que se operam mecanismos de resistência à imposição cultural da língua imperial espanhola e da língua fang que poderemos observar em universos que surgem como impostos.

Mas outras particularidades da "ilha do mar Atlante" merecem destaque. O fato social total insular de Ano Bom presente no romance de Juan Tomás Ávila Laurel mais além dos universos masculino e feminino do espaço privado e familiar da casa, dominado pela figura do avô e pelas figuras das mães - é colocado em evidência ao leitor pelas atividades quotidianas da construção masculina de barcos e respetiva colocação no mar, pelas reuniões de homens no vidjil $^{19}$, do cultivo a cargo das mulheres e da solidariedade em momentos menos prósperos, que poderão ser, por sua vez, considerados como um sistema de prestação total, recuperando um sistema de dádiva teorizado por Marcel Mauss ${ }^{20}$.

Para além destes intercâmbios quotidianos, assinalem-se os decorrentes da construção atual mundo atlântico da colonialidade. Neste caso, o peixe é um elemento central, já que era o alimento básico da população e que nem sempre existia ao largo de uma ilha que tem bancos suficientes para alimentar os seus. Esta carência torna-se uma quase obsessão, não apenas pela fome, mas também pela incompreensão que gera não ter peixe para comer em terra quando existe no mar, mas está à mercê da indústria pesqueira corporativa capitalista.

Denuncia-se o fato de a ilha não pertencer a quem nela vive, mas a outros tentáculos que acionam o que se considera como mundo da colonialidade e das teias de exploração. Os barcos, que pertencem a "blancos", permanecem nas águas

19 Juan Tomás Ávila Laurel apresenta o vidjil como "esa casa de recreo que los hombres tenían al borde de la playa" (Arde el Monte de Noche, p. 32).

20 Para Mauss (2001, p. 67-69), o sistema de prestação total implica, necessariamente, três obrigações, e é nestas que se centra o circuito da dádiva: a obrigação de dar, a de receber e a de retribuir. Receber, dar e retribuir são direitos e deveres que se confluem, onde tudo é matéria de transmissão e de entrega (comida, bens, solo, serviços, trabalho, etc.). O chamado "sistema das prestações totais" é "o mais antigo sistema de economia e de direito possível de comprovar e conceber", para onde a sociedade, na sua opinião, deveria regressar, uma vez que sempre foi e sempre será um princípio "sair de si, dar, livre e obrigatoriamente" (MAUSS, 2001, p. 181-182). 
territoriais ao largo da ilha de Ano Bom enquanto há peixe para levar. E retiram "directamente de nuestra despensa, de nuestro mar", porque se crê que a ilha não é de ninguém (Arde el Monte de Noche, p. 50-51). Os possessivos são decisivos para marcar as propriedades do nós que, por esta via da exploração capitalista global, é espoliado. A troco do peixe do seu mar, recebem alguma comida ou cigarros. A negociação tem os termos definidos: os barcos vão roubar; os homens da ilha que vão ao barco buscar coisas vão "ejercer de mendigos" (Arde el Monte de Noche, p. 68).

Já que a terra é um pedaço pequeno, caberá nestas formulações imperialistas a dominação e a extração de recursos marítimos. E esta caraterística marca a dominação sobre a ilha de Ano Bom. E é ainda uma manifestação de imperialismo, já que, para além da extração de matéria, há um mecanismo de regulação da vida da população pelos ciclos de chegada e de partida dos barcos, que coincidem com ciclos de menor e de maior carestia.

Na diegese do romance, a depredação do mar é seguida pela desolação do monte ardido que lhe dá o título. $O$ mar e o monte têm em comum o facto de os seus frutos não serem de ninguém (Arde el Monte de Noche, p. 50-63). Dos seres humanos que vivem situações de carestia incompreensível. Disto exemplo é o episódio central da narrativa, um surto de cólera que assola a ilha. Um caso que confirma a depredação e o isolamento da população, respirando-se a morte. Inclusive, a madeira que antes servia para a construção dos barcos agora é a matéria-prima dos ataúdes. A enumeração dos mortos e a sucessão de frases negativas colocam o acento na forma como a negação se torna numa ação ininterrupta (cf. Arde el Monte de Noche, p. 9299).

Como componente do universo enfermo da negação e da privação a que pertence a extração pesqueira, o incêndio ou a cólera, regista-se ainda o assassínio impune de uma presumível bruxa, num ambiente geral de miséria crescente, devida a factos externos às dinâmicas da população, condicionando-a no cerne da globalidade colonial. Não se trata apenas da dependência denunciada das visitas ao largo e sem tocar dos barcos que roubam a troco de alguns bens. Vai-se mais longe, como se os ambô fossem uma população destinada a "vivir sin nada" (Arde el Monte de Noche, p. 207). Ou na obscuridade, omnipresente na explicação detalhada de acontecimentos da infância, considerada como "alguien más" (Arde el Monte de Noche, p. 156).

$E$ agora sim, regresso à epígrafe que havia escolhido para este texto ${ }^{21}$. Mediante a invisibilidade e pelas conclusões referentes à exposição das redes de poder dispostas nessa ilha do mar Atlante, torna-se evidente que estamos diante da construção, através do registo literário, de uma geografia e de uma gramática de rede de colonialidade. Com esta observação, não quero dizer que esta ilha sirva como uma metáfora do sistema colonial e da atual rede sistémica de colonialidade com acento no poder, no ser e no saber ${ }^{22}$. É antes a construção de uma gramática geossituada da

${ }^{21}$ Que agora recordo: "Todo en mi isla daba miedo. En realidad vivir en la oscuridad es hacerlo de espaldas a la historia. Y es que no creo que nadie pueda contar lo que hace en la oscuridad, pues no conocería todos los detalles de lo que ocurre en ella" (Arde el Monte de Noche, p. 158).

22 Santiago Castro-Gómez (2007, p. 79-80) apresenta uma estrutura triangular da colonialidade, cujos vértices são o ser, o saber e o poder. Mais do que uma estrutura, opto por abordar a 
rede heterárquica que constitui ainda hoje o mundo de dominação colonial atlântico, já que se trata de um local de vivência e de enunciação sobre a experiência da subjugação.

Aníbal Quijano (2007, p. 120-125) desenvolve diversas associações da colonialidade do poder, como a universalidade do capitalismo e a decorrente classificação hierárquica do mundo, que se mede na articulação entre a política e a cultura, na distribuição mundial do trabalho, nas relações de género, nas relações culturais ou entre sujeitos, no domínio ou na corporeidade. É neste sentido que se hierarquizam caraterísticas fenotípicas, que se territoralizam espaços que pertencem à rede colonial, que se naturaliza a apropriação do espaço ou que se criam laços de dependência, despojando-se (ou tentando-se despojar, melhor) as populações dos seus imaginários.

É da descrição dos contextos de privação, de isolamento e de rapina, impeditivos de um quotidiano regular, nesta rede que Quijano apresenta, que nasce a ideia de que a marca forte deste romance de Juan Tomás Ávila Laurel seja a dos condenados da terra. Aliando os universos culturais particulares da ilha do mar de Atlante já apresentados e a perspetiva sistémica que nos é oferecida do regime autocrata da Guiné Equatorial nas teias da colonialidade, poder-se-á afirmar que Juan Tomás Ávila Laurel nos traz uma experiência e uma raiz que transmite a pluriversalidade do mundo, se quisermos recorrer ao termo cunhado por Walter Mignolo (2007, p. 45) para expressar as aberturas diversas às localidades, às línguas, às memórias, às formas de organização social, ou aos "esplendores y miserias de los legados imperiales".

Um desses legados é a solidão da ilha diante da carência generalizada. Afinal, "me di cuenta de que las gentes de mi isla solamente se tenían a sí mismos para mirar por ellos" (Arde el Monte de Noche: 49). É assim que neste romance lemos a história do grupo que poderá considerar-se como o dos sem história (seguindo Eric Wolf) ou dos subalternos (na terminologia de Gayatri Spivak). No entanto, prefiro buscar a Frantz Fanon (2002) a expressão condenados da terra. Porque há que afirmar a história e passar as teias da subalternidade pelo desafio à lógica da colonialidade que marca as ausências que se produzem nos relatos da modernidade ${ }^{23}$. E porque se trata do outro lado do mundo compartimentado, maniqueísta e imóvel tão bem descrito nos seus efeitos e lutas por Fanon (2002, p. 43-54).

Os condenados da terra compõem a pertença ao grupo dos "não ser", numa demarcação racial. Hoje continuam assim. Disso exemplo é a quase ausência de notícias na atualidade sobre as manifestações da sociedade civil em países como o Gabão ou os Camarões, a título de exemplo, contra os aspetos menos claros dos regimes políticos, ao mesmo tempo em que os meios de comunicação de massas

colonialidade como um sistema, ainda que buscando a Castro-Gómez a tríplice construção desta rede de dominação.

${ }^{23}$ De acordo com Walter Mignolo (2007, p. 17), a colonialidade é a outra cara da modernidade e que se marca pelas ausências. No entanto, não poderemos esquecer de que se trata da modernidade centrada no Atlântico, que envolve a invenção da América (como no título de Mignolo, La Idea de América Latina) e a de África (como no título de Valentin Mudimbe, The Invention of Africa). 
exploram e geram comentários sobre as massivas revoltas na Tunísia, no Egito ou na Líbia. Contudo, e como ensina Gloria Anzaldúa a respeito de lutas pelas fronteiras na sua exploração de novas e necessárias consciências, "The possibilities are numerous once we decide to act and not react" (2007, p. 101).

Muito se insiste na impossibilidade de trajetórias heterogéneas num espaço global ${ }^{24}$ e da enunciação de um discurso que dê nota da localidade e da vivência no chamado Sul Global. Mas de um Sul Global composto de realidades tão próprias como as que se assinalam neste texto. E de vozes como as de Juan Tomás Ávila Laurel. Portanto, a impossibilidade terá de ser relativizada.

É desta forma que a construção do condenado da terra ou do sujeito colonial ${ }^{25}$ se faz na narrativa de alguém que pertence a esse universo. Não se trata da vitimização, mas sim da negociação desta vivência tornada conceito na obra de Juan Tomás Ávila Laurel. Não se trata de sujeitos privados da história. São sujeitos que a constroem ao nível das vivências e da língua da ilha. Não é UMA ilha do mar atlante. É, para Juan Tomás Ávila, A ilha do mar Atlante. Um signo de particularidade. E de narrativa. Tal como é ilha de Bioko, onde sempre escrevia o seu blog Malabo, ao qual dá continuidade fora da Guiné Equatorial.

É assim que o conceito de sujeito colonial se poderá resgatar a partir do conceito de nativo ou de negro, de Frantz Fanon, que pressupõe a sua consideração como objeto da situação colonial, obviando-se a sua humanização. De assinalar que a situação colonial não se refere a um tempo de antes da independência, mas plasma a atualidade e a pós-colónia como o resultado de uma trajetória de relações de violência, de subjugação, de imposição de consciência e de exclusão, que marcam a associação entre o sujeito (colonial) e a coisa ${ }^{26}$.

A este respeito, Achille Mbembe (2001, p. 41-44) expõe as continuidades do sistema colonial na inserção de países africanos no sistema internacional, de que são exemplos programas de ajuda, de investimento económico ou de suporte a elites políticas autocratas, os donos das soberanias privatizadas. Assim se abrem todos os canais para a manutenção de relações de dependência e de frustração de quem aspira a uma sociedade mais equilibrada. A época de neocolonialismo e os seus vetores encontra eco na privatização das soberanias, como é exemplo a Guiné Equatorial, joga com os direitos sobre a vida e a morte ${ }^{27}$, já que a regulação social, cultural e política se faz de maneira a que as teias do poder disponham dos seres humanos como

\footnotetext{
${ }^{24}$ Veja-se o seguinte exemplo: "in order to argue that one potentially significant contribution of global South discourse is to render the impossibility of its own trajectories across heterogeneous global spaces. In other words, global South discourse stands to recognize, as an effect of the neoliberal globalization in which it seeks to intervene, the irreducible limits on thinking the South from within the institutions of the North and the discursive practices they sustain" (CHERNIAVSKY, 2007, p. 77).

25 Trata-se de sujeitos coloniais pela inscrição da diferença colonial, ou seja, a institucionalização de diferenças numa base de subalternização (cf. MALDONADO-TORRES, 2007, p. 132-133).

26 Sobre a pós-colónia como uma identificação com um trajecto histórico que emerge da experiência da colonização e das formas de relação pautadas pela violência, consulte-se MBEMBE, 2001.

27 De acordo com Achille Mbembe (2001, p. 34, 54, 129), soberania, vida e morte, em articulação, são signos que caraterizam a pós-colónia e a sua máquina de regulação social, cultural e política.
} 
condenados da terra. É desta maneira que se segue a distinção colonial entre quem é ser e quem não é.

No caso de Ano Bom e da narrativa de Juan Tomás Ávila Laurel, a colonialidade do ser leva-se mais longe do que simplesmente (ou complexamente, melhor) baseada no que tomamos como raça, enquanto categoria simbólica. Se considerarmos, com Nelson Maldonado-Torres (2007, p. 151), que a súmula da ideia de colonialidade do ser reside nos projetos históricos em que emerge e que salientam a separação dos sujeitos pela cor, nas suas manifestações, nas diversas dimensões que constituem as suas vidas, verificamos que se vai mais além do que esta questão. A marcação da diferença e da sujeição marca-se em pautas mais complexas, num sistema político etnocrata no qual as considerações sobre a pertença se dispõem ao serviço do lado mais obscuro da globalidade petrolífera, do funcionamento da sociedade internacional, dos negócios pesqueiros e da militarização. É assim que na colonialidade do ser se encontram vários matizes e graduações mais além da raça. É que estamos diante de lugares dos quais emergem vozes e projetos. E Juan Tomás Ávila Laurel, sendo um "livre", ou seja, sem adscrição a qualquer partido político, apresenta claramente nos seus textos um projeto político para o seu país e para as teias globais. Basta que o leiamos com atenção e não apenas tentando buscar as críticas que faz ao quotidiano vivido e às redes de dominação. Em suma, através de Juan Tomás Ávila Laurel, e mediante a conjugação entre os géneros escolhidos para a escrita, a reflexão sobre a identidade insular e a construção da história realiza-se a partir da enunciação dos condenados da terra que relevam a noção de propriedade e a de autoctonia.

Estas ideias poderão ser compreendidas, desde logo, nos registos ensaísticos deste autor e mais disponíveis à aldeia global através do seu blog, dos quais se salienta o comentário político e social sobre a Guiné Equatorial, tanto a níveis micro, correspondentes a circunstâncias específicas da vida de Malabo, como a um plano macro, respeitantes a formas de regulamentação governamental num quadro global. Disso é exemplo a primeira crónica de Malabo, publicada no dia 30 de Novembro de 2009, na qual denuncia o neocolonialismo e a manutenção de redes globais de poder que permitem que o circuito de proventos económicos fique nas mãos de poucos. Facto a que associa o racismo global que impede uma visão da Guiné Equatorial como um país no qual as pessoas tenham direito a viver com dignidade, ou seja, com vida. Como escreve em outro romance, no qual o narrador é fang, a vida significa "dignidad y tierra, aire y luz" (Avión de Ricos, Ladrón de Cerdos, p. 110). A mesma ideia se regista em Frantz Fanon (2002, p. 47):

"Pour le peuple colonisé la valeur la plus essentielle, parce que la plus concrète, c'est d'abord la terre : la terre qui doit assurer le pain et, bien sûr, la dignité".

Ou, se quisermos em fá d'ambô, para que a dignidade seja de todos, são necessários ampã e tela! 


\section{Referências}

ANZALDÚA, Gloria. Borderlands: The New Mestiza = La Frontera. São Francisco: Aunt Lute Books, 2007.

ÁVILA LAUREL, Juan Tomás. Cómo Convertir este País en un Paraíso. Otras Reflexiones sobre Guinea Ecuatorial. Malabo: Ediciones Pángola, 2005.

Avión de Ricos, Ladrón de Cerdos. Barcelona: El Cobre, 2008.

Arde el Monte de Noche. Madrid: Calambur, 2009.

. La isla de Annobón, el refugio de las musas. In Afro-Hispanic Review, Volume

28, Número 2. Nashville: Vanderbilt University, 2009, p. 331-334.

BOLEKIA BOLEKÁ, Justo. Aproximación a la Historia de Guinea Ecuatorial. Salamanca: Amarú Ediciones, 2003.

CALDEIRA, Arlindo Manuel. Organizing freedom: de facto independence on the island of Ano Bom (Annobón) during the eighteenth and nineteenth centuries. In: AfroHispanic Review, Volume 28, Número 2- Nashville: Vanderbilt University, 2009, p. 293-310.

CASTRO-GÓMEZ, Santiago. Decolonizar la universidad. La hybris del punto cero y el diálogo de saberes. In: CASTRO-GÓMEZ, Santiago e GROSFOGUEL, Ramón (Ed.). El Giro Decolonial. Reflexiones para una Diversidad Epistémica Más Allá del Capitalismo Global. Bogotá: Siglo de Hombre Editores, Universidad Central, Instituto de Estudios Sociales Contemporáneos, Pontificia Universidad Javeriana e Instituto Pensar: 2007, p. 79-91.

CHERNIAVSKY, Eva. "The Romance of the Subaltern in the Twilight of Citizenship". In The Global South, Volume 1, números 1 e 2. Bloomington: Indiana University Press, 2007.

FANON, Frantz. Les Damnés de la Terre. Paris: La Découverte, 2002.

GARUBA, Harry. "The Island Writes Back: Discourse/Power and Marginality in Wole Soyinka's The Swamp Dwellers, Derek Walcott's The Sea at Dauphin, and Athol Fugard's The Island". In Research in African Literatures, Volume 32, Número 4. Bloomington: Indiana University Press, 2001, p. 61-76.

GILROY, Paul. The Black Atlantic. Modernity and Double Consciousness. Cambridge e Massachusetts: Harvard University Press, 2002.

KABUNDA, Mbuyi. "África en el sistema internacional de la posguerra fría o las respuestas africanas a los desafíos de la globalización". In INIESTA, Ferran (Ed.). La Frontera Ambigua. Tradición y Democracia en África. Barcelona: Bellaterra, 2007, p. 35-61.

MALDONADO-TORRES, Nelson. "Sobre la colonialidad del ser: contribuciones al desarrollo de un concepto". In CASTRO-GÓMEZ, Santiago e GROSFOGUEL, Ramón (Ed.). El Giro Decolonial. Reflexiones para una Diversidad Epistémica Más Allá del Capitalismo Global. Bogotá: Siglo de Hombre Editores, Universidad Central, Instituto 
de Estudios Sociales Contemporáneos, Pontificia Universidad Javeriana e Instituto Pensar, 2007, p. 127-167.

MAUSS, Marcel. Ensaio Sobre a Dádiva. Lisboa: Edições 70, 2001.

MBEMBE, Achille. On the Postcolony. Berkeley: University of California Press, 2001.

MIGNOLO, Walter. La idea de América Latina. La herida colonial y la opción decolonial. Barcelona: Gedisa, 2007.

QUIJANO, Aníbal, "Colonialidad del poder y clasificación social". In CASTRO-GÓMEZ, Santiago e GROSFOGUEL, Ramón (Ed.). El Giro Decolonial. Reflexiones para una Diversidad Epistémica Más Allá del Capitalismo Global. Bogotá: Siglo de Hombre Editores, Universidad Central, Instituto de Estudios Sociales Contemporáneos, Pontificia Universidad Javeriana e Instituto Pensar, 2007, p. 93-126.

SANDOVAL, Chela. Methodology of the Oppressed. Minneapolis: University of Minnesota Press, 2000.

THIONG'O, Ngugi Wa. Decolonising the Mind: The Politics of Language in African Literature. Londres, Nairobi, Portsmouth N. H. e Harare: James Currey e Heinemann, 1987.

\title{
ANEXO: CARTA A JOSÉ BONO MARTÍNEZ, PRESIDENTE DEL PARLAMENTO ESPAÑOL
}

\author{
EXCELENTÍSMO SEÑOR DON JOSÉ BONO MARTÍNEZ:
}

Ya que cree tanto en la solvencia moral del presidente Obiang, quien lleva en el poder desde el año 1979, le pedimos de todo corazón que hagas las gestiones y presiones para constituir en Guinea un gobierno de transición en el que no deben formar parte ninguno de los que han ostentado cargos en estos 32 años.

Esta, como creerá, no es una exigencia política, sino social y moral. Ya no podemos seguir viviendo bajo una dictadura que nos come el alma.

Señor Bono, lo único que deseamos es que consiga que Obiang, su hijo Teodorín, la primera dama Constancia, los hermanos y primos generales y coroneles que sostienen este incalificable poder consigan un asilo en un país seguro. Creemos que con la tercera parte del dinero guardado en el extranjero por uno solo de ellos dará para que vivan hasta el resto de sus días. El resto del dinero tendrá que ser devuelto al país. Pida a los gobiernos de los países implicados en esta masiva evasión de dinero que colaboren y tengan fe en nuestras peticiones, tanto en la asignación de un mínimo para que vivan como en la restitución del resto al país.

No exigimos que sean juzgados, porque hasta ahora no es una exigencia planteada por ninguna organización. Cómo podían plantearlo si los legitimáis con vuestros gestos. Entonces no tendría sentido plantearlo después, porque sería una hipocresía mayor.

Con el dinero recuperado, señor Bono, se construirán escuelas y se formarán maestros y profesores y sacaremos del ejército guineano a estos miles de jóvenes 
secuestrados por la miseria y les daremos educación y formación. Y daremos educación a los niños guineanos, faltos de atención en un país rico como éste.

Con este dinero y con lo que queda, instituiremos la justicia y lucharemos contra la impunidad. Formaremos a jueces y robusteceremos nuestro sistema judicial.

Con este dinero, señor Bono, cultivaremos nuestras tierras, aseguraremos nuestras despensas y lucharemos contra la degradación ambiental. En definitiva, nos procuraremos lo indispensable para una vida mínimamente digna.

Con un plan de un gobierno más humano, haremos que la vida en Guinea sea digna, porque creemos que hay recursos para ello.

Este no es un plan de Gobierno, señor Bono, pero si se les deja hacer a los que más saben y quieren, lo que se diga de Guinea será de mutuo beneficio para España y para todos los guineanos que viven aquí y en muchas regiones y provincias españolas esperando un milagro que no se dará si no hacemos, hace usted, lo que debe, aprovechando tu visita.

No es justo dejar mi vida en sus manos, señor Bono, pero tengo que reconocer que lo que pase de ella tendrá usted mucho que contar.

Malabo, 11 de febrero 2011

Juan Tomás Ávila Laurel

\section{Título}

La isla del mar Atlante, de Juan Tomás Ávila Laurel: autobiografía y ciberactivismo ensayístico en Guinea Ecuatorial.

\section{Resumen}

En este texto, dedicado al escritor Juan Tomás Ávila Laurel, se destaca su posición en el campo de la literatura de Guinea Ecuatorial, al ser el escritor crítico de la dictadura de Teodoro Obiang con más visibilidad internacional que vive en el país, circunstancia que todavía se subraya por su ciberactivismo. Basándose esencialmente en registros ensayísticos e en la novela autobiográfica Arde el Monte de Noche, este texto intenta problematizar, de acuerdo con el compromiso social que subyaz a la producción escrita de Juan Tomás Ávila Laurel, la colonialidad vivida por una parte de la humanidad, así como la emergencia de voces y de acciones que subvierten los cuadros de ausencias de los condenados de la tierra en actuales sistemas de dominación y de univocidad.

\section{Palabras-clave}

Guinea Ecuatorial. Autobiografía. Colonialidad. Compromiso social.

Recebido em 02.10.2011. Aprovado em 29.11.2011. 